\title{
Matching Diabetes and Alcoholism: Oxidative Stress, Inflammation, and Neurogenesis Are Commonly Involved
}

\author{
Jorge M. Barcia, ${ }^{1}$ Miguel Flores-Bellver, ${ }^{1}$ Maria Muriach, ${ }^{2}$ \\ Javier Sancho-Pelluz, ${ }^{1}$ Daniel Lopez-Malo, ${ }^{1}$ Alba C. Urdaneta, ${ }^{1}$ Natalia Martinez-Gil, ${ }^{1}$ \\ Sandra Atienzar-Aroca, ${ }^{1}$ and Francisco J. Romero ${ }^{1}$ \\ ${ }^{1}$ Facultad de Medicina y Odontología, Universidad Católica de Valencia “San Vicente Mártir", C/Quevedo 2, 46001 Valencia, Spain \\ ${ }^{2}$ Unidad Predepartamental de Medicina, Universitat Jaume I, 12071 Castellón de la Plana, Spain
}

Correspondence should be addressed to Francisco J. Romero; f.romero@ucv.es

Received 11 July 2014; Revised 18 September 2014; Accepted 18 November 2014

Academic Editor: Yuh-Lien Chen

Copyright (c) 2015 Jorge M. Barcia et al. This is an open access article distributed under the Creative Commons Attribution License, which permits unrestricted use, distribution, and reproduction in any medium, provided the original work is properly cited.

Diabetes and alcohol misuse are two of the major challenges in health systems worldwide. These two diseases finally affect several organs and systems including the central nervous system. Hippocampus is one of the most relevant structures due to neurogenesis and memory-related processing among other functions. The present review focuses on the common profile of diabetes and ethanol exposure in terms of oxidative stress and proinflammatory and prosurvival recruiting transcription factors affecting hippocampal neurogenesis. Some aspects around antioxidant strategies are also included. As a global conclusion, the present review points out some common hits on both diseases giving support to the relations between alcohol intake and diabetes.

\section{Introduction}

In accordance with the International Diabetes Federation, latest diabetes statistics indicates that 382 million people are affected by diabetes in 2013. Alcohol use disorder (formerly called alcohol dependence or alcohol abuse) is the most abundant mental disorder in America, where approximately $14 \%$ of the population meets chronic alcoholic criteria during some period of their lives $[1,2]$. It is closely related to several organic diseases and is involved in almost $50 \%$ of traffic accidents and the majority of homicides, suicides, and domestic violence cases [3]. Alcoholism and diabetes can affect several organs and systems. Alcohol exposure and diabetes can both be associated with cognitive impairment. In fact, diabetes-associated cognitive decline describes a state of cognitive impairment $[4,5]$. Furthermore, diabetes increases the risk of Alzheimer's disease, vascular dementia, and any other type of dementia [6,7]. Alcoholic dementia and ethanol related cognitive decline are also described [8-10].

The central nervous system (CNS) is especially vulnerable to oxidative damage as a result of its high oxygen consumption rate, its abundant lipid content, and relative paucity of antioxidant enzymes as compared to other tissues. Neural tissue is particularly sensitive to oxidative insults; in fact reactive oxygen species (ROS) are involved in many diseases finally affecting the CNS $[11,12]$. Under these two pathological conditions, cellular stress triggers mitochondrial oxidative damage, which may result in apoptosis and/or necrosis [1315].

\section{Diabetes and Ethanol Exposure Promote Oxidative Stress: AGE and Aldehydes}

It is well documented that diabetes and alcohol exposure are accompanied by alterations in the redox status. Hyperglycemia and ethanol exposure reduce antioxidant levels and increase the production of free radicals with subsequent activation of redox-sensitive genes [15-21].

Glutathione system, including both reduced and oxidized forms (GSH and GSSG, resp.) and the glutathione peroxidase enzyme (GPx), is one of the most important cellular antioxidant defense systems due to its capacity of trapping ROS. GSH 
is ubiquitously present including the central nervous tissue [22]. It is well documented that hippocampal GSH/GSSG ratio and GPx activity are significantly reduced in diabetes or by ethanol exposure $[15,18-21,23-26]$. Interestingly, this decrease can be prevented by antioxidant treatment in both cases $[17,19,26,27]$, indicating that ROS could be at least partially responsible of the GSH content and GPx activity decreases.

ROS usually react with lipids, a process known as lipid peroxidation. Since the CNS is particularly rich in fatty acids, this peroxidation results in aldehyde production, for example, malondialdehyde (MDA) and 4-hydroxyalkenals such as 4-hydroxy-nonenal (4-HNE). These end-products may create adducts leading to DNA alterations (for a review see [28]) and protein modifications. These facts can produce enzymatic activity alterations or lack of DNA sequencerecognizing, among other side effects. In this way, 4-HNE inhibits Aktl by competitive inhibition of ATP at the kinase domain of ATP binding sites resulting in increased ROS levels and cell death [29]. ROS production decreased antioxidant defense and increased lipid peroxidation and membrane degeneration, leading to cellular damage/death in diabetes or ethanol exposure [30-32]. In fact, mitochondrial dysfunction and reduced ATP biosynthesis have been implicated in diabetes and ethanol exposure $[15,33]$. Accumulation of lipid peroxidation products such as 4 -HNE and MDA in mitochondria has also been reported in diabetic patients, possibly causing further damage to mitochondrial genetic and metabolic systems $[34,35]$. In this sense, recent data from our laboratory indicate a marked increase in 4-HNE aggregates after ethanol exposure in a human retinal pigment epithelial cell line (ARPE-19) accompanied by mitochondrial degeneration and mitophagy [36].

One of the main questions concerning ethanol and diabetes is the one related to how hyperglycemia and ethanol exposure exert primarily their negative effects. Evidences are accumulating pointing to the role of oxidative stress and proinflammatory mechanisms on both pathological conditions, but little is known about the molecular mechanisms.

Circulating proteins or lipids can be modified by circulating sugars and even aldehydes such as acetaldehyde [37, 38]. These products are known as advanced glycation end products (AGEs) [39, 40]. AGEs can produce ROS and AGEs can bind to specific cell surface receptors (RAGE) [40, 41]. AGEs produce ROS via $\mathrm{NAD}(\mathrm{P}) \mathrm{H}$ oxidase and also activate nuclear factor kappa B (NF- $\kappa$ B) $[20,42]$. Further support for this idea is the finding of increased expression of serum AGEs in alcoholic patients and RAGE in the prefrontal cortex of human alcoholic patients $[43,44]$. In fact, some toxic effects promoted by experimental diabetes are increased by ethanol administration [45].

\section{Cytochrome p450 2E1 (CYP2E1) Is Commonly Implicated}

Another relevant enzyme related to diabetes and ethanol exposure is cytochrome P450. This is a family of enzymes involved in the oxidative metabolism of both endogenous and xenobiotic products [46-48]. Particularly involved in EtOH oxidation, CYP2E1 isoform assumes an important role in metabolizing ethanol being considered as a major component of the microsomal ethanol-oxidizing system (MEOS) [49, 50].

Increased expression of hepatic CYP2E1 in human or experimental diabetes and alcohol abusers has been reported [51-54]. Ethanol-induced CYP2E1 gene transcription is ROSmediated and therefore CYP2E1 induction is accompanied by more ROS production and vice versa [55]. In fact, diallyl sulphide (DAS), a competitive inhibitor of CYP2E1, can directly block ROS production and also inhibit CYP2E1 induction [55]. A parallel increase of CYP2E1 expression and ROS production in brain, kidney, and liver of streptozotocininduced diabetic rats has been also reported and these increases can be blocked by ascorbic acid [56, 57]. So CYP2E1 and ROS are reciprocally modulated in diabetes and ethanol exposure. Interestingly, NF- $\kappa \mathrm{B}$ regulates CYP2E1 expression by different ways, being implicated in several diseases including diabetes [58]. Considering that CYP2E1 is not only found in liver, but can be also considered almost ubiquitously present, the possibility that an ethanol extrahepatic detoxifying activity could be present in other tissues, including the brain, must be taken into account.

\section{Hippocampal Neurogenesis Is Affected in Diabetes and Ethanol Exposure}

Hippocampus is part of the temporal lobe being considered crucial for several cognitive processes as well as for spatial navigation and memory processing [59]. Hippocampus is particularly affected in several diseases, for example, Alzheimer's disease and diabetes, or in alcohol use disorder $[60,61]$. One of the particularities of this neural structure is that referred to neurogenesis. Hippocampus shares this privilege with the subventricular zone (SVZ). Concretely, the subgranular zone (SGZ) of the dentate gyrus presents a discrete stem cell population [62]. Newborn subgranular cells differentiate to neurons being finally integrated into the granular cell layer (GCL) thickness [63]. Although the concrete function or meaning of this neuronal incorporation still remains unclear [64], the inhibition of stem cell proliferation or the death of newborn cells is accompanied by an impairment of hippocampal-dependent functions. Focusing on diabetes and alcohol consumption, it is well established that both conditions can affect cognitive processes and neurogenesis.

A classical experimental task evaluating hippocampaldependent functions is the popular Morris water maze test, based on the location of an underwater hidden platform. Independently of the swimming speed, animals treated with ethanol exhibit more latency time to find the platform. In other words they need more time to learn. This task is considered a good tool assessing hippocampal function. Giving support to this phenomenon is the finding that hippocampal long term potentiation (LTP) is also disrupted. Experimental LTP is considered as a good tool to approach synaptic plasticity and therefore learning processes [65]. 
Interestingly the simultaneous triad consisting of neurogenesis reduction, spatial navigation impairment, and hippocampal LTP disruption is usually present in diabetes and ethanol exposure $[17,19,66-68]$, suggesting close relationship among them. Furthermore, all these alterations can be prevented by antioxidant treatment adding more evidence to this relationship $[19,68]$. Although it seems clear that ROS are relevant in these processes, evidences are also accumulating pointing to the glucocorticoid pathway, since it has been demonstrated how those hippocampal alterations (including neurogenesis, LTP, and water maze test) in type I and II diabetes are normalized when glucocorticoid levels are in a physiological range [69]. The negative effects of high glucocorticoid levels on hippocampal neurogenesis and synaptic plasticity are well documented [69-72]. Ethanol exposure also alters the hypothalamic pituitary axis (HPA): in a rat model of binge drinking, increased corticosterone levels led to dentate gyrus degeneration and this phenomenon seemed to be mediated by type II glucocorticoid receptor [73], in agreement with that occurring in diabetes.

\section{CREB, NF- $\kappa$ B, and Nrf2 Are Altered in Diabetes and Alcohol Exposure}

NF- $\kappa \mathrm{B}$ and $\mathrm{cAMP}$ responsive element-binding protein (CREB) are both transcription factors, respectively, related with proinflammatory and prosurvival genes.

CREB-related genes are transcribed by the phosphorylation of CREB ( $\mathrm{p}$-CREB). Those CREB-related genes encoding neurotrophins are generally related to neuronal survival, cell death protection, and neural plasticity, as are the brain derived neurotrophic factor (BDNF), B-cell lymphoma 2 (Bcl-2) protein, nerve growth factor (NGF), and vascular endothelial growth factor (VEGF) genes $[74,75]$.

$\mathrm{CREB} / \mathrm{p}-\mathrm{CREB}$ signaling has been related to neurite outgrowth, learning-memory and LTP [76-78].

Although $\mathrm{NF}-\kappa \mathrm{B}$ is a transcriptional factor typically implicated in inflammatory and immune responses [79], NF$\kappa \mathrm{B}$ is also involved in neuroprotection, being implicated in cell division, synaptic plasticity, neurite growth, and formation of functional dendritic spines [79-83].

$\mathrm{NF}-\kappa \mathrm{B}$ can be activated by oxidative stress or other signals such as cytokines or glutamate $[79,82,84]$. In fact, NF- $\kappa \mathrm{B}$ is induced in several conditions such as neurodegenerative diseases and brain injury $[81,85,86]$.

As indicated above, ethanol exposure and diabetes promote oxidative stress in the CNS and particularly in the hippocampus. At the same time both, ethanol exposure and diabetes, decrease hippocampal CREB phosphorylation [18, $87,88]$ while they increase NF- $\kappa$ B activity $[17,18,88]$. Additionally, deregulation of inflammatory genes has been found in hippocampi of alcoholic patients [89] and furthermore prefrontal cortices from alcoholic patients also show NF$\kappa \mathrm{B} / \mathrm{p} 50$ downregulation [90].

Ethanol-induced p-CREB decrease is accompanied by reductions in BDNF gene expression contributing to hippocampal neurotoxicity [91]. In fact, hippocampal BDNF is also decreased in a type 2 diabetes animal model and it is associated with hippocampal dependent memory impairment [92, 93]. Furthermore, caffeine and huperzine restore hippocampal-dependent memory impairment via BDNF [94, 95].

Nuclear factor (erythroid-derived 2)-like 2 (Nrf2) binds to the antioxidant response element (ARE) sequence promoting the transcription of antioxidant-related proteins as $\mathrm{NAD}(\mathrm{P}) \mathrm{H}$ quinone oxidoreductase 1, gluthatione $\mathrm{S}$ transferase, or GPx among others [96]. According to Cederbaum [97] Nrf2 plays a key role in the adaptive response against increased oxidative stress caused by CYP2E1 in HepG2 cells. Nrf2 activation inhibits NF- $\kappa$ B activation by reducing $\mathrm{ROS}$ and by inhibiting $\mathrm{I} \kappa \mathrm{B}$ degradation $[97,98]$. $\mathrm{NF}-\kappa \mathrm{B}$ also binds to ARE sequence competing with Nrf2 [99] and therefore the result of this balance may lead to proinflammation or antioxidant defense responses.

Focusing on hippocampal neurogenesis, a positive regulation of cell proliferation has been demonstrated by $\mathrm{p}$ CREB in the SGZ [100]. Stressing the role of CREB in this process, hippocampal neurogenesis is also a GABACREB dependent process regulating maturation and survival of newly generated subgranular neurons [101]. All these evidences give support to the possibility that ethanol and diabetes may reduce hippocampal neurogenesis in the same way.

According to previous reports [80-82], NF- $\kappa$ B may play different roles in hippocampal neurogenesis depending on the cell stage. In neuronal progenitor cells (NPC) it regulates axogenesis and maturation, whereas in mature granule cells (MGC) it regulates neuroprotection and synaptic transmission. In fact $\mathrm{NF}-\kappa \mathrm{B}$ inhibition promotes dentate gyrus atrophy [80].

How some genes related to neurogenesis and synaptic plasticity are altered by diabetes as well as how dietary supplementation with resveratrol normalized them has been described. Furthermore, proinflammatory genes from the Jak-Stat pathway are also repressed after resveratrol administration [102]. In this sense, it is interesting to note that resveratrol acts as a mixed agonist/antagonist for estrogen receptors [103] that induces $\mathrm{Bcl}-2$ expression via CREB and Akt phosphorylation [104], so its action is not solely by direct ROS trapping [105].

Regarding the CREB-related pathway, it has been shown that Nrf2 and NF- $\kappa \mathrm{B}$ compete for the transcriptional coactivator CREB-binding protein (CBP) [106]. Additionally, $\mathrm{CBP} / \mathrm{p} 300$ complex is a histone acetyltransferase (HAT) associated with $\mathrm{CREB}, \mathrm{Nrf} 2, \mathrm{NF}-\kappa \mathrm{B}$, and $\mathrm{AP}-1$ gene transcription [107]. However, CBP is also associated with glucocorticoid receptors [108], resulting in HAT activity inhibition with subsequent transcriptional blockade of the genes above; interestingly, curcumin has been described as an inhibitor of $\mathrm{CBP} / \mathrm{p} 300$ [109]. Several data are focusing on the neuroprotective role of curcumin improving hippocampal neurogenesis in some animal models such as ischemic brain injury [110] and chronic stress [111]. Curcumin alleviates neuropathic pain by reducing spinal BDNF and cox- 2 gene expression in a rat model of neuropathic pain [112], and interestingly the Akt/Nrf2 pathway is involved in neuroprotection after brain ischemia [113]. However and surprisingly, hippocampal 


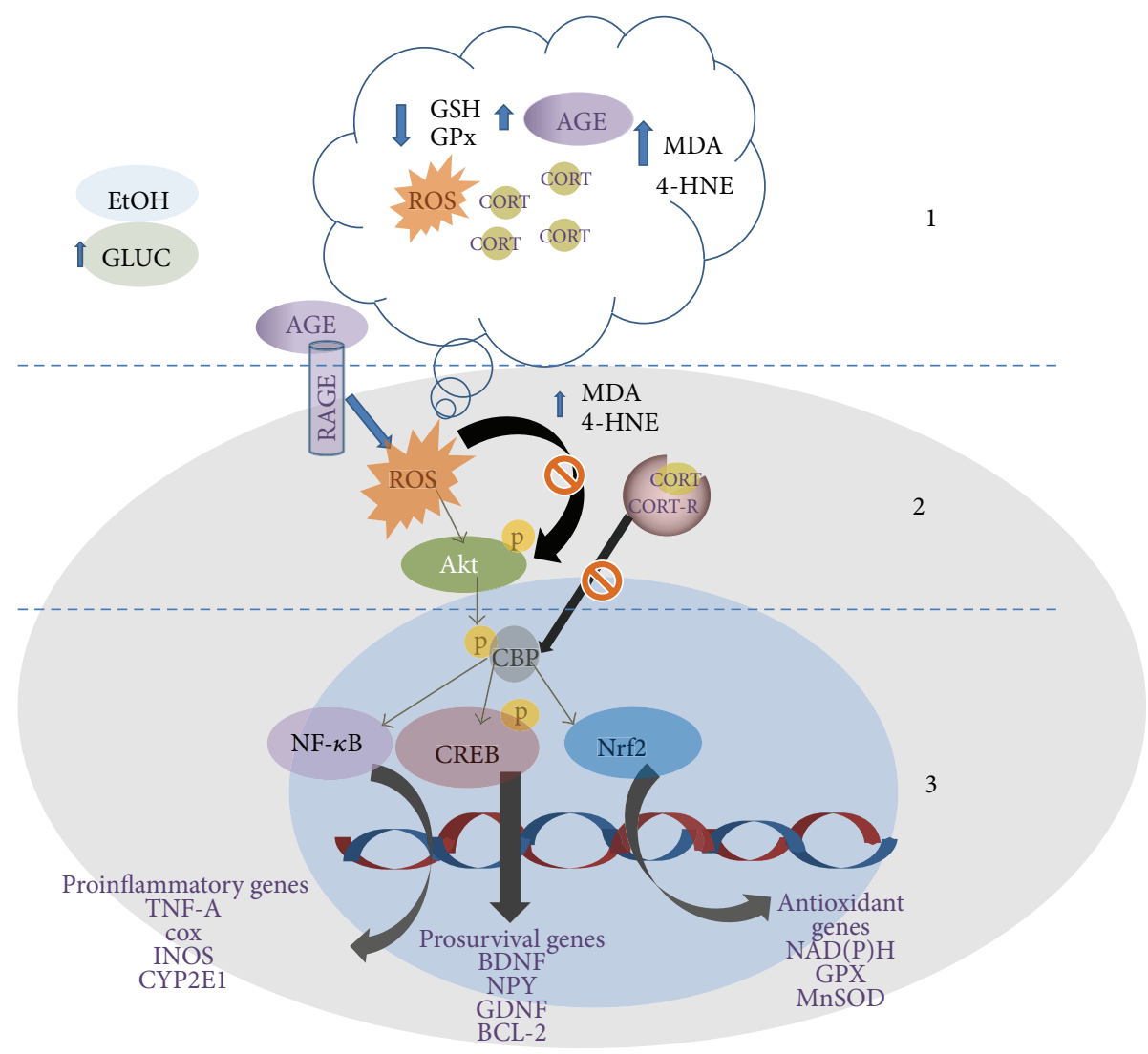

FIGURE 1: Scheme summarizing common pathways implicated in oxidative stress, inflammation, and antioxidant responses. 1. Circulating ethanol and high glucose levels lead to ROS production, antioxidant defense decay, AGE, and aldehyde production (4-HNE, MDA). Alterations on the hypothalamic pituitary axis (HPA) produce glucocorticoid release. 2. RAGE activation and ROS activate Akt but increased levels of 4-HNE; MDA can block Akt phosphorylation. 3. CBP is an acetyl transferase (HAT) that depends on p-Akt. CBP is necessary for p-CREB, Nf- $\kappa \mathrm{B}$, and Nrf2 allowing transcription of proinflammatory or anti-inflammatory genes. Glucocorticoid receptors inhibit CBP activity blocking transcription. Since Nf- $\kappa$ B, p-CREB, and Nrf2 compete for CBP the balance on proinflammation versus anti-inflammation transcription is compromised. GSH: reduced glutathione; NF- $\kappa \mathrm{B}$ : nuclear factor kappa B; MDA: malondialdehyde; ROS: reactive oxygen species; MnSOD: manganese superoxide dismutase; TNF $\alpha$ : tumor necrosis factor alpha; COX: cyclooxygenase; iNOS: inducible nitric oxide synthase; GPx: glutathione peroxidase; BDNF: brain-derived neurotrophic factor; NGF: nerve growth factor; Bcl-2: B-cell lymphoma 2; CORT: corticosteroid; CORT-R: corticosteroid receptor; P-CREB: phospho-cAMP response element-binding; CBP: CREB-binding protein; Nrf2: nuclear factor erythroid-derived 2; 4-HNE: 4-hydroxynonenal; Akt: protein kinase B; CYP2E1: cytochrome P450 2E1; RAGE: receptor for advanced glycation end products.

neurogenesis inhibition, under chronic stress conditions, can be reversed by curcumin via increasing BDNF [110].

High glucose and ethanol exposure promote glucose misbalance, HPA deregulation with metabolic and molecular changes affecting different systems but particularly CNS. ROS and oxidative stress misbalance are present as common background feature and may be the reason of the similarities observed between high glucose and ethanol exposure such as the presence of AGE, good outcome to antioxidant strategies, and hippocampal neurogenesis inhibition. Since alcoholism and diabetes in humans are long lasting diseases with a "waveform-like" behavior in terms of intermittent relapseabstinence, binge or chronic drinking, randomly insulin control, or uncontrolled glycemia, it seems plausible that alcoholism and diabetes may lead to neuroadaptive changes.

Transcription signaling for CREB, Nrf2, and NF- $\kappa \mathrm{B}$ dependent genes is commonly regulated by CBP activity and furthermore the competition for DNA sequences might explain the outcome of these diseases. Exposure to high glucose levels or ethanol seems to act on a similar way activating similar genes and some antioxidants as curcumin or resveratrol are effective by activating up-stream molecules modulating those aforementioned genes. ROS inhibition significantly alleviates many of the deleterious effects promoted by hyperglycemia or ethanol exposure. So the combination of direct ROS scavengers and antioxidants as curcumin or resveratrol can not only block cellular damage but also modulate gene transcription activity (see Figure 1).

\section{Final Summary}

Several cellular and molecular alterations are shared during ethanol exposure or under diabetic conditions. Hippocampal 
neurogenesis is negatively affected and CREB/p-CREB, NF$\kappa \mathrm{B}$, Nrf2, and CYP $2 \mathrm{E} 1$ are involved and modified in both situations. Oxidative stress is a key factor of these situations, since the addition of antioxidants (trapping ROS) can reverse or normalize all these aforementioned alterations. Furthermore, evidences are also focusing on downstream effects of antioxidants in terms of activation-repression of transcription factors such as CREB or Nrf2, making of antioxidant therapies a good tool against neural and functional alterations in diabetes and alcohol-related memory or cognitive impairments. Diabetes and chronic ethanol exposure affect different organs and systems and some of their negative effects can be improved or prevented by antioxidant therapies. Knowing how antioxidants can prevent those negative effects or elicit cellular protective responses may be helpful for future development of new therapeutic tools against these two diseases affecting millions of people worldwide.

Additionally, experimental and clinical studies strongly indicate a close relationship between alcohol intake and risk of diabetes development [114-117]. Considering all data available, and reviewed herein (molecular signaling, genes, and transcription factors), it seems plausible that all overlapping mechanisms of alcohol intake and diabetes could explain this relationship.

\section{Conflict of Interests}

The authors declare that there is no conflict of interests regarding the publication of this paper.

\section{References}

[1] M. Lejoyeux, M. Mc Loughlin, and J. Adès, "Epidemiology of behavioral dependence: literature review and results of original studies," European Psychiatry, vol. 15, no. 2, pp. 129-134, 2000.

[2] D. Antai, G. B. Lopez, J. Antai, and D. S. Anthony, "Alcohol drinking patterns and differences in alcohol-related harm: a population-based study of the United States," BioMed Research International, vol. 2014, Article ID 853410, 11 pages, 2014.

[3] R. Room, T. Babor, and J. Rehm, "Alcohol and public health," The Lancet, vol. 365, no. 9458, pp. 519-530, 2005.

[4] L. Bordier, J. Doucet, J. Boudet, and B. Bauduceau, "Update on cognitive decline and dementia in elderly patients with diabetes," Diabetes and Metabolism, vol. 40, no. 5, pp. 331-337, 2014.

[5] G. S. Mijnhout, P. Scheltens, M. Diamant et al., "Diabetic encephalopathy: a concept in need of a definition," Diabetologia, vol. 49, no. 6, pp. 1447-1448, 2006.

[6] G. J. Biessels, A. C. Kappelle, B. Bravenboer, D. W. Erkelens, and W. H. Gispen, "Cerebral function in diabetes mellitus," Diabetologia, vol. 37, no. 7, pp. 643-650, 1994.

[7] G. Cheng, C. Huang, H. Deng, and H. Wang, "Diabetes as a risk factor for dementia and mild cognitive impairment: a metaanalysis of longitudinal studies," Internal Medicine Journal, vol. 42, no. 5, pp. 484-491, 2012.

[8] E. Kuźma, D. J. Llewellyn, K. M. Langa, R. B. Wallace, and I. A. Lang, "History of alcohol use disorders and risk of severe cognitive impairment: a 19-year prospective cohort study," The
American Journal of Geriatric Psychiatry, vol. 22, no. 10, pp. 1047-1054, 2014.

[9] S. Gupta and J. Warner, "Alcohol-related dementia: a 21stcentury silent epidemic?" British Journal of Psychiatry, vol. 193, no. 5, pp. 351-353, 2008.

[10] A. Pierucci-Lagha and C. Derouesné, "Alcoholism and aging. 2. Alcoholic dementia or alcoholic cognitive impairment?" Psychol Neuropsychiatr Vieil, vol. 1, no. 4, pp. 237-249, 2003.

[11] J. Yuan and B. A. Yankner, "Apoptosis in the nervous system," Nature, vol. 407, no. 6805, pp. 802-809, 2000.

[12] L. L. Dugan, S. L. Sensi, L. M. T. Canzoniero et al., "Mitochondrial production of reactive oxygen species in cortical neurons following exposure to N-methyl-D-aspartate," The Journal of Neuroscience, vol. 15, no. 10, pp. 6377-6388, 1995.

[13] M. Merad-Boudia, A. Nicole, D. Santiard-Baron, C. Saillé, and I. Ceballos-Picot, "Mitochondrial impairment as an early event in the process of apoptosis induced by glutathione depletion in neuronal cells: relevance to Parkinson's disease," Biochemical Pharmacology, vol. 56, no. 5, pp. 645-655, 1998.

[14] L. Cui, H. Jeong, F. Borovecki, C. N. Parkhurst, N. Tanese, and D. Krainc, "Transcriptional repression of PGC-1alpha by mutant huntingtin leads to mitochondrial dysfunction and neurodegeneration," Cell, vol. 127, no. 1, pp. 59-69, 2006.

[15] I. Almansa, A. Fernández, C. García-Ruiz et al., "Brain mitochondrial alterations after chronic alcohol consumption," Journal of Physiology and Biochemistry, vol. 65, no. 3, pp. 305-312, 2009.

[16] D. Bonnefont-Rousselot, "Glucose and reactive oxygen species," Current Opinion in Clinical Nutrition and Metabolic Care, vol. 5, no. 5, pp. 561-568, 2002.

[17] M. Muriach, F. Bosch-Morell, G. Alexander et al., "Lutein effect on retina and hippocampus of diabetic mice," Free Radical Biology and Medicine, vol. 41, no. 6, pp. 979-984, 2006.

[18] R. Alvarez-Nölting, E. Arnal, J. M. Barcia, M. Miranda, and F. J. Romero, "Protection by DHA of early hippocampal changes in diabetes: possible role of CREB and NF- $\kappa$ B," Neurochemical Research, vol. 37, no. 1, pp. 105-115, 2012.

[19] S. Johnsen-Soriano, F. Bosch-Morell, M. Miranda et al., "Ebselen prevents chronic alcohol-induced rat hippocampal stress and functional impairment," Alcoholism: Clinical and Experimental Research, vol. 31, no. 3, pp. 486-492, 2007.

[20] M. Muriach, M. Flores-Bellver, F. J. Romero, and J. M. Barcia, "Diabetes and the brain: oxidative stress, inflammation, and autophagy," Oxidative Medicine and Cellular Longevity, vol. 2014, Article ID 102158, 9 pages, 2014.

[21] I. Almansa, J. M. Barcia, R. López-Pedrajas, M. Muriach, M. Miranda, and F. J. Romero, "Naltrexone reverses ethanolinduced rat hippocampal and serum oxidative damage," Oxidative Medicine and Cellular Longevity, vol. 2013, Article ID 296898, 5 pages, 2013.

[22] R. Dringen and J. Hirrlinger, "Glutathione pathways in the brain," Biological Chemistry, vol. 384, no. 4, pp. 505-516, 2003.

[23] M. Sommavilla, M. V. Sánchez-Villarejo, I. Almansa et al., "The effects of acute ethanol exposure and ageing on rat brain glutathione metabolism," Free Radical Research, vol. 46, no. 9, pp. 1076-1081, 2012.

[24] J. S. S. Kumar and V. P. Menon, "Effect of diabetes on levels of lipid peroxides and glycolipids in rat brain," Metabolism: Clinical and Experimental, vol. 42, no. 11, pp. 1435-1439, 1993.

[25] T. K. Makar, K. Rimpel-Lamhaouar, D. G. Abraham, V. S. Gokhale, and A. J. L. Cooper, "Antioxidant defense systems in 
the brains of type II diabetic mice," Journal of Neurochemistry, vol. 65, no. 1, pp. 287-291, 1995.

[26] M. Miranda, M. Muriach, I. Almansa et al., "CR-6 protects glutathione peroxidase activity in experimental diabetes," Free Radical Biology and Medicine, vol. 43, no. 11, pp. 1494-1498, 2007.

[27] M. Assunção, M. J. Santos-Marques, V. de Freitas et al., "Red wine antioxidants protect hippocampal neurons against ethanol-induced damage: a biochemical, morphological and behavioral study," Neuroscience, vol. 146, no. 4, pp. 1581-1592, 2007.

[28] M. Dizdaroglu and P. Jaruga, "Mechanisms of free radicalinduced damage to DNA," Free Radical Research, vol. 46, no. 4, pp. 382-419, 2012.

[29] M. P. Kashyap, A. K. Singh, D. K. Yadav et al., "4-Hydroxy-trans2-nonenal (4-HNE) induces neuronal SH-SY5Y cell death via hampering ATP binding at kinase domain of Akt1," Archives of Toxicology, 2014.

[30] M.-C. Desco, M. Asensi, R. Márquez et al., "Xanthine oxidase is involved in free radical production in type 1 diabetes: protection by allopurinol," Diabetes, vol. 51, no. 4, pp. 1118-1124, 2002.

[31] J. V. Hunt, R. T. Dean, and S. P. Wolff, "Hydroxyl radical production and autoxidative glycosylation. Glucose autoxidation as the cause of protein damage in the experimental glycation model of diabetes mellitus and ageing," Biochemical Journal, vol. 256, no. 1, pp. 205-212, 1988.

[32] S. P. Wolff, "Diabetes mellitus and free radicals. Free radicals, transition metals and oxidative stress in the aetiology of diabetes mellitus and complications," British Medical Bulletin, vol. 49, no. 3, pp. 642-652, 1993.

[33] M. S. Santos, D. L. Santos, C. M. Palmeira, R. Seiça, A. J. Moreno, and C. R. Oliveira, "Brain and liver mitochondria isolated from diabetic Goto-Kakizaki rats show different susceptibility to induced oxidative stress," Diabetes/Metabolism Research and Reviews, vol. 17, no. 3, pp. 223-230, 2001.

[34] N. Traverso, S. Menini, P. Odetti, M. A. Pronzato, D. Cottalasso, and U. M. Marinari, "Lipoperoxidation in hepatic subcellular compartments of diabetic rats," Free Radical Biology and Medicine, vol. 26, no. 5-6, pp. 538-547, 1999.

[35] N. Traverso, S. Menini, P. Odetti, M. A. Pronzato, D. Cottalasso, and U. M. Marinari, "Diabetes impairs the enzymatic disposal of 4-hydroxynonenal in rat liver," Free Radical Biology and Medicine, vol. 32, no. 4, pp. 350-359, 2002.

[36] M. Flores-Bellver, L. Bonet-Ponce, J. M. Barcia et al., "Autophagy and mitochondrial alterations in human retinal pigment epithelial cells induced by ethanol: implications of 4-hydroxy-nonenal," Cell Death \& Disease, vol. 5, Article ID e1328, 2014.

[37] M. Takeuchi, T. Watai, N. Sasaki et al., "Neurotoxicity of acetaldehyde-derived advanced glycation end products for cultured cortical neurons," Journal of Neuropathology and Experimental Neurology, vol. 62, no. 5, pp. 486-496, 2003.

[38] N. Hayashi, J. George, M. Takeuchi et al., "Acetaldehydederived advanced glycation end-products promote alcoholic liver disease," PLoS ONE, vol. 8, no. 7, Article ID e70034, 2013.

[39] A. M. Schmidt, O. Hori, J. Brett, S. D. Yan, J.-L. Wautier, and D. Stern, "Cellular receptors for advanced glycation end products-implications for induction of oxidant stress and cellular dysfunction in the pathogenesis of vascular lesions," Arteriosclerosis, Thrombosis, and Vascular Biology, vol. 14, no. 10, pp. 1521-1528, 1994.
[40] R. Singh, A. Barden, T. Mori, and L. Beilin, "Advanced glycation end-products: a review," Diabetologia, vol. 44, no. 2, pp. 129-146, 2001.

[41] M. Brownlee, H. Vlassara, and A. Cerami, "Nonenzymatic glycosylation products on collagen covalently trap low-density lipoprotein," Diabetes, vol. 34, no. 9, pp. 938-941, 1985.

[42] A. Goldin, J. A. Beckman, A. M. Schmidt, and M. A. Creager, "Advanced glycation end products: sparking the development of diabetic vascular injury," Circulation, vol. 114, no. 6, pp. 597605, 2006.

[43] K. Marta, Z. Tomáš, P. Petr et al., "Advanced glycation endproducts in patients with chronic alcohol misuse," Alcohol and Alcoholism, vol. 39, no. 4, pp. 316-320, 2004.

[44] R. P. Vetreno, L. Qin, and F. T. Crews, "Increased receptor for advanced glycation end product expression in the human alcoholic prefrontal cortex is linked to adolescent drinking," Neurobiology of Disease, vol. 59, pp. 52-62, 2013.

[45] V. R. Gopal and M. Indira, "Investigations on the correlation of advanced glycated end products (AGE) associated fluorescence with blood glucose and oxidative stress in ethanol-administered diabetic rats," Experimental and Toxicologic Pathology, vol. 62, no. 2, pp. 157-162, 2010.

[46] A. I. Cederbaum, "Alcohol metabolism," Clinics in Liver Disease, vol. 16, no. 4, pp. 667-685, 2012.

[47] F. P. Guengerich, D.-H. Kim, and M. Iwasaki, "Role of human cytochrome P-450 IIE1 in the oxidation of many low molecular weight cancer suspects," Chemical Research in Toxicology, vol. 4, no. 2, pp. 168-179, 1991.

[48] D. R. Koop, E. T. Morgan, G. E. Tarr, and M. J. Coon, "Purification and characterization of a unique isozyme of cytochrome P-450 from liver microsomes of ethanol-treated rabbits," The Journal of Biological Chemistry, vol. 257, no. 14, pp. 8472-8480, 1982.

[49] E. Albano, "New concepts in the pathogenesis of alcoholic liver disease," Expert Review of Gastroenterology and Hepatology, vol. 2, no. 6, pp. 749-759, 2008.

[50] C. S. Lieber, E. Rubin, and L. M. DeCarli, "Hepatic microsomal ethanol oxidizing system (MEOS): differentiation from alcohol dehydrogenase and NADPH oxidase," Biochemical and Biophysical Research Communications, vol. 40, no. 4, pp. 858-865, 1970.

[51] G. Ekstrom, T. Cronholm, and M. Ingelman-Sundberg, "Hydroxyl-radical production and ethanol oxidation by liver microsomes isolated from ethanol-treated rats," Biochemical Journal, vol. 233, no. 3, pp. 755-761, 1986.

[52] C. Ioannides, C. R. Barnett, A. Irizar, and P. R. Flatt, "Drug metabolism and chemical toxicity in diabetes," Drugs, Diet and Disease, vol. 2, pp. 330-353, 1995.

[53] H. Raza, I. Ahmed, M. S. Lakhani, A. K. Sharma, D. Pallot, and W. Montague, "Effect of bitter melon (Momordica Charantia) fruit juice on the hepatic cytochrome P450dependent monooxygenases and glutathione $S$-transferases in Streptozotocin-induced diabetis rats," Biochemical Pharmacology, vol. 52, no. 10, pp. 1639-1642, 1996.

[54] H. Raza, I. Ahmed, A. John, and A. K. Sharma, "Modulation of xenobiotic metabolism and oxidative stress in chronic streptozotocin-induced diabetic rats fed with Momordica charantia fruit extract," Journal of Biochemical and Molecular Toxicology, vol. 14, no. 3, pp. 131-139, 2000.

[55] M. Jin, A. Ande, A. Kumar, and S. Kumar, "Regulation of cytochrome P450 2el expression by ethanol: role of oxidative stress-mediated pkc/jnk/sp1 pathway," Cell Death and Disease, vol. 4, no. 3, article e554, 2013. 
[56] T. Ahn, C.-H. Yun, and D.-B. Oh, "Tissue-specific effect of ascorbic acid supplementation on the expression of cytochrome P450 2E1 and oxidative stress in streptozotocin-induced diabetic rats," Toxicology Letters, vol. 166, no. 1, pp. 27-36, 2006.

[57] H. Raza and A. John, "Glutathione metabolism and oxidative stress in neonatal rat tissues from streptozotocin-induced diabetic mothers," Diabetes/Metabolism Research and Reviews, vol. 20, no. 1, pp. 72-78, 2004.

[58] B. N. M. Zordoky and A. O. S. El-Kadi, "Role of NF- $\kappa$ B in the regulation of cytochrome P450 enzymes," Current Drug Metabolism, vol. 10, no. 2, pp. 164-178, 2009.

[59] J. O'Keefe and L. Nadel, The Hippocampus as a Cognitive Map, Oxford University Press, Oxford, UK, 1978.

[60] A. Kamal, G. J. Biessels, S. E. J. Duis, and W. H. Gispen, "Learning and hippocampal synaptic plasticity in streptozotocindiabetic rats: Interaction of diabetes and ageing," Diabetologia, vol. 43, no. 4, pp. 500-506, 2000.

[61] W.-J. Zhang, Y.-F. Tan, J. T. Y. Yue, M. Vranic, and J. M. Wojtowicz, "Impairment of hippocampal neurogenesis in streptozotocin-treated diabetic rats," Acta Neurologica Scandinavica, vol. 117, no. 3, pp. 205-210, 2008.

[62] M. S. Kaplan and J. W. Hinds, "Neurogenesis in the adult rat: electron microscopic analysis of light radioautographs," Science, vol. 197, no. 4308, pp. 1092-1094, 1977.

[63] H. A. Cameron, C. S. Woolley, B. S. McEwen, and E. Gould, "Differentiation of newly born neurons and glia in the dentate gyrus of the adult rat," Neuroscience, vol. 56, no. 2, pp. 337-344, 1993.

[64] W. Deng, J. B. Aimone, and F. H. Gage, "New neurons and new memories: how does adult hippocampal neurogenesis affect learning and memory?" Nature Reviews Neuroscience, vol. 11, no. 5, pp. 339-350, 2010.

[65] T. V. P. Bliss and G. L. Collingridge, "A synaptic model of memory: long-term potentiation in the hippocampus," Nature, vol. 361, no. 6407, pp. 31-39, 1993.

[66] S. Sasaki-Hamada, H. Sacai, and J.-I. Oka, "Diabetes onset influences hippocampal synaptic plasticity in streptozotocintreated rats," Neuroscience, vol. 227, pp. 293-304, 2012.

[67] H. Kalalian-Moghaddam, T. Baluchnejadmojarad, M. Roghani, F. Goshadrou, and A. Ronaghi, "Hippocampal synaptic plasticity restoration and anti-apoptotic effect underlie berberine improvement of learning and memory in streptozotocindiabetic rats," European Journal of Pharmacology, vol. 698, no. 1-3, pp. 259-266, 2013.

[68] D. G. Herrera, A. G. Yagüe, S. Johnsen-Soriano et al., "Selective impairment of hippocampal neurogenesis by chronic alcoholism: protective effects of an antioxidant," Proceedings of the National Academy of Sciences of the United States of America, vol. 100, no. 13, pp. 7919-7924, 2003.

[69] A. M. Stranahan, T. V. Arumugam, R. G. Cutler, K. Lee, J. M. Egan, and M. P. Mattson, "Diabetes impairs hippocampal function through glucocorticoid-mediated effects on new and mature neurons," Nature Neuroscience, vol. 11, no. 3, pp. 309$317,2008$.

[70] E. Gould, H. A. Cameron, D. C. Daniels, C. S. Woolley, and B. S. McEwen, "Adrenal hormones suppress cell division in the adult rat dentate gyrus," Journal of Neuroscience, vol. 12, no. 9, pp. 3642-3650, 1992.

[71] E. Gould, C. S. Woolley, and B. S. McEwen, "Adrenal steroids regulate postnatal development of the rat dentate gyrus: I. Effects of glucocorticoids on cell death," Journal of Comparative Neurology, vol. 313, no. 3, pp. 479-485, 1991.
[72] D.-J. Saaltink and E. Vreugdenhil, "Stress, glucocorticoid receptors, and adult neurogenesis: a balance between excitation and inhibition?" Cellular and Molecular Life Sciences, vol. 71, no. 13, pp. 2499-2515, 2014.

[73] A. Cippitelli, R. Damadzic, C. Hamelink et al., "Binge-like ethanol consumption increases corticosterone levels and neurodegneration whereas occupancy of type II glucocorticoid receptors with mifepristone is neuroprotective," Addiction Biology, vol. 19, no. 1, pp. 27-36, 2014.

[74] B. E. Lonze and D. D. Ginty, "Function and regulation of CREB family transcription factors in the nervous system," Neuron, vol. 35, no. 4, pp. 605-623, 2002.

[75] T. Mantamadiotis, T. Lemberger, S. C. Bleckmann et al., "Disruption of CREB function in brain leads to neurodegeneration," Nature Genetics, vol. 31, no. 1, pp. 47-54, 2002.

[76] C. F. Stevens, "CREB and memory consolidation," Neuron, vol. 13, no. 4, pp. 769-770, 1994.

[77] D. A. Frank and M. E. Greenberg, "CREB: a mediator of longterm memory from mollusks to mammals," Cell, vol. 79, no. 1, pp. 5-8, 1994.

[78] S.-H. Ghil, B.-J. Kim, Y.-D. Lee, and H. Suh-Kim, "Neurite outgrowth-induced by cyclic AMP can be modulated by the $\alpha$ subunit of Go," Journal of Neurochemistry, vol. 74, no. 1, pp. 151$158,2000$.

[79] L. A. J. O’Neill and C. Kaltschmidt, "NF- $\kappa$ B: a crucial transcription factor for glial and neuronal cell function," Trends in Neurosciences, vol. 20, no. 6, pp. 252-258, 1997.

[80] Y. Imielski, J. C. Schwamborn, P. Lüningschrör et al., "Regrowing the adult brain: NF- $\kappa$ B controls functional circuit formation and tissue homeostasis in the dentate gyrus," PLOS ONE, vol. 7, no. 2, Article ID e30838, 2012.

[81] B. Kaltschmidt and C. Kaltschmidt, "NF-kappaB in the nervous system," Cold Spring Harbor perspectives in biology, vol. 1, no. 3, Article ID a001271, 2009.

[82] M. P. Mattson and M. K. Meffert, "Roles for NF- $\kappa$ B in nerve cell survival, plasticity, and disease," Cell Death and Differentiation, vol. 13, no. 5, pp. 852-860, 2006.

[83] N. Gavaldà, H. Gutierrez, and A. M. Davies, "Developmental switch in NF- $\kappa$ B signalling required for neurite growth," Development, vol. 136, no. 20, pp. 3405-3412, 2009.

[84] E. Hinoi, V. J. Balcar, N. Kuramoto, N. Nakamichi, and Y. Yoneda, "Nuclear transcription factors in the hippocampus," Progress in Neurobiology, vol. 68, no. 2, pp. 145-165, 2002.

[85] K. Terai, A. Matsuo, E. G. McGeer, and P. L. McGeer, "Enhancement of immunoreactivity for NF- $\kappa \mathrm{B}$ in human cerebral infarctions," Brain Research, vol. 739, no. 1-2, pp. 343-349, 1996.

[86] J. R. Bethea, M. Castro, R. W. Keane, T. T. Lee, W. D. Dietrich, and R. P. Yezierski, "Traumatic spinal cord injury induces nuclear factor- $\kappa \mathrm{B}$ activation," Journal of Neuroscience, vol. 18, no. 9, pp. 3251-3260, 1998.

[87] S. Bison and F. T. Crews, "Alcohol withdrawal increases neuropeptide Y immunoreactivity in rat brain," Alcoholism: Clinical and Experimental Research, vol. 27, no. 7, pp. 1173-1183, 2003.

[88] G. J. Francis, J. A. Martinez, W. Q. Liu et al., "Intranasal insulin prevents cognitive decline, cerebral atrophy and white matter changes in murine type I diabetic encephalopathy," Brain, vol. 131, no. 12, pp. 3311-3334, 2008.

[89] J. N. McClintick, X. Xuei, J. A. Tischfield et al., "Stress-response pathways are altered in the hippocampus of chronic alcoholics," Alcohol, vol. 47, no. 7, pp. 505-515, 2013. 
[90] S. Heck, K. Bender, M. Kullmann, M. Göttlicher, P. Herrlich, and A. C. B. Cato, "I $\kappa \mathrm{B} \alpha$-independent downregulation of NF$\kappa \mathrm{B}$ activity by glucocorticoid receptor," The EMBO Journal, vol. 16, no. 15, pp. 4698-4707, 1997.

[91] J. Zou and F. Crews, "CREB and NF- $\kappa$ B transcription factors regulate sensitivity to excitotoxic and oxidative stress induced neuronal cell death," Cellular and Molecular Neurobiology, vol. 26, no. 4-6, pp. 385-405, 2006.

[92] G. Winocur, C. E. Greenwood, G. G. Piroli et al., "Memory impairment in Obese Zucker rats: an investigation of cognitive function in an animal model of insulin resistance and obesity," Behavioral Neuroscience, vol. 119, no. 5, pp. 1389-1395, 2005.

[93] Y. F. Zhen, J. Zhang, X. Y. Liu et al., "Low BDNF is associated with cognitive deficits in patients with type 2 diabetes," Psychopharmacology, vol. 227, no. 1, pp. 93-100, 2013.

[94] X.-Y. Mao, D.-F. Cao, X. Li et al., "Huperzine a ameliorates cognitive deficits in streptozotocin-induced diabetic rats," International Journal of Molecular Sciences, vol. 15, no. 5, pp. 76677683, 2014.

[95] G. A. Moy and E. C. McNay, "Caffeine prevents weight gain and cognitive impairment caused by a high-fat diet while elevating hippocampal BDNF," Physiology \& Behavior, vol. 109, no. 1, pp. 69-74, 2013.

[96] T. Nguyen, P. J. Sherratt, and C. B. Pickett, "Regulatory mechanisms controlling gene expression mediated by the antioxidant response element," Annual Review of Pharmacology and Toxicology, vol. 43, pp. 233-260, 2003.

[97] A. Cederbaum, "Nrf2 and antioxidant defense against CYP2E1 toxicity," Expert Opinion on Drug Metabolism and Toxicology, vol. 5, no. 10, pp. 1223-1244, 2009.

[98] V. Ganesh Yerra, G. Negi, S. S. Sharma, and A. Kumar, "Potential therapeutic effects of the simultaneous targeting of the Nrf2 and NF- $\kappa$ B pathways in diabetic neuropathy," Redox Biology, vol. 1, no. 1, pp. 394-397, 2013.

[99] G.-H. Liu, J. Qu, and X. Shen, "NF- $\kappa$ B/p65 antagonizes Nrf2ARE pathway by depriving CBP from Nrf2 and facilitating recruitment of HDAC3 to MafK," Biochimica et Biophysica Acta, vol. 1783, no. 5, pp. 713-727, 2008.

[100] S. Nakagawa, J.-E. Kim, R. Lee et al., "Regulation of neurogenesis in adult mouse hippocampus by cAMP and the cAMP response element-binding protein," Journal of Neuroscience, vol. 22, no. 9, pp. 3673-3682, 2002.

[101] R. Jagasia, K. Steib, E. Englberger et al., "GABA-cAMP response element-binding protein signaling regulates maturation and survival of newly generated neurons in the adult hippocampus," The Journal of Neuroscience, vol. 29, no. 25, pp. 7966-7977, 2009.

[102] J. Thomas, M. L. Garg, and D. W. Smith, "Dietary resveratrol supplementation normalizes gene expression in the hippocampus of streptozotocin-induced diabetic C $57 \mathrm{Bl} / 6$ mice," Journal of Nutritional Biochemistry, vol. 25, no. 3, pp. 313-318, 2014.

[103] J. L. Bowers, V. V. Tyulmenkov, S. C. Jernigan, and C. M. Klinge, "Resveratrol acts as a mixed agonist/antagonist for estrogen receptors $\alpha$ and $\beta$," Endocrinology, vol. 141, no. 10, pp. 3657-3667, 2000.

[104] S. Das, G. A. Cordis, N. Maulik, and D. K. Das, "Pharmacological preconditioning with resveratrol: role of CREB-dependent Bcl-2 signaling via adenosine $\mathrm{A}_{3}$ receptor activation," American Journal of Physiology-Heart and Circulatory Physiology, vol. 288, no. 1, pp. H328-H335, 2005.

[105] S. S. Leonard, C. Xia, B.-H. Jiang et al., "Resveratrol scavenges reactive oxygen species and effects radical-induced cellular responses," Biochemical and Biophysical Research Communications, vol. 309, no. 4, pp. 1017-1026, 2003.

[106] A. G. Ziady, A. Sokolow, S. Shank et al., "Interaction with CREB binding protein modulates the activities of Nrf2 and NF- $\kappa \mathrm{B}$ in cystic fibrosis airway epithelial cells," American Journal of Physiology: Lung Cellular and Molecular Physiology, vol. 302, no. 11, pp. L1221-L1231, 2012.

[107] A. Ökvist, S. Johansson, A. Kuzmin et al., "Neuroadaptations in human chronic alcoholics: dysregulation of the NF- $\kappa$ B system," PLoS ONE, vol. 2, no. 9, article e930, 2007.

[108] S. Rivest, "Regulation of innate immune responses in the brain," Nature Reviews Immunology, vol. 9, no. 6, pp. 429-439, 2009.

[109] M. G. Marcu, Y.-J. Jung, S. Lee et al., "Curcumin is an inhibitor of p300 histone acetylatransferase," Medicinal Chemistry, vol. 2, no. 2, pp. 169-174, 2006.

[110] J. Wu, Q. Li, X. Wang et al., "Neuroprotection by curcumin in ischemic brain injury involves the Akt/Nrf2 pathway," PLoS ONE, vol. 8, no. 3, Article ID e59843, 2013.

[111] Y. Xu, B. Ku, L. Cui et al., "Curcumin reverses impaired hippocampal neurogenesis and increases serotonin receptor $1 \mathrm{~A}$ mRNA and brain-derived neurotrophic factor expression in chronically stressed rats," Brain Research, vol. 1162, no. 1, pp. 9$18,2007$.

[112] X. Zhu, Q. Li, R. Chang et al., "Curcumin alleviates neuropathic pain by inhibiting $\mathrm{p} 300 / \mathrm{CBP}$ histone acetyltransferase activityregulated expression of BDNF and Cox-2 in a rat model," PLoS ONE, vol. 9, no. 3, Article ID e91303, 2014.

[113] J. Wu, Q. Li, X. Wang et al., "Neuroprotection by curcumin in ischemic brain injury involves the Akt/Nrf2 pathway," PLoS ONE, vol. 8, no. 3, Article ID e59843, 2013.

[114] S.-J. Kim, A. Ju, S.-G. Lim, and D.-J. Kim, "Chronic alcohol consumption, type 2 diabetes mellitus, insulin-like growth factor-I (IGF-I), and growth hormone (GH) in ethanol-treated diabetic rats," Life Sciences, vol. 93, no. 21, pp. 778-782, 2013.

[115] A. M. Hodge, G. K. Dowse, V. R. Collins, and P. Z. Zimmet, "Abnormal glucose tolerance and alcohol consumption in three populations at high risk of non-insulin-dependent diabetes mellitus," American Journal of Epidemiology, vol. 137, no. 2, pp. 178-189, 1993.

[116] F. O. Risinger and C. L. Cunningham, "Genetic differences in ethanol-induced hyperglycemia and conditioned taste aversion," Life Sciences, vol. 50, no. 16, pp. PL113-PL118, 1992.

[117] M. Cullmann, A. Hilding, and C.-G. Östenson, "Alcohol consumption and risk of pre-diabetes and type 2 diabetes development in a Swedish population," Diabetic Medicine, vol. 29, no. 4, pp. 441-452, 2012. 


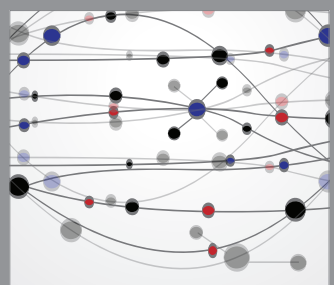

The Scientific World Journal
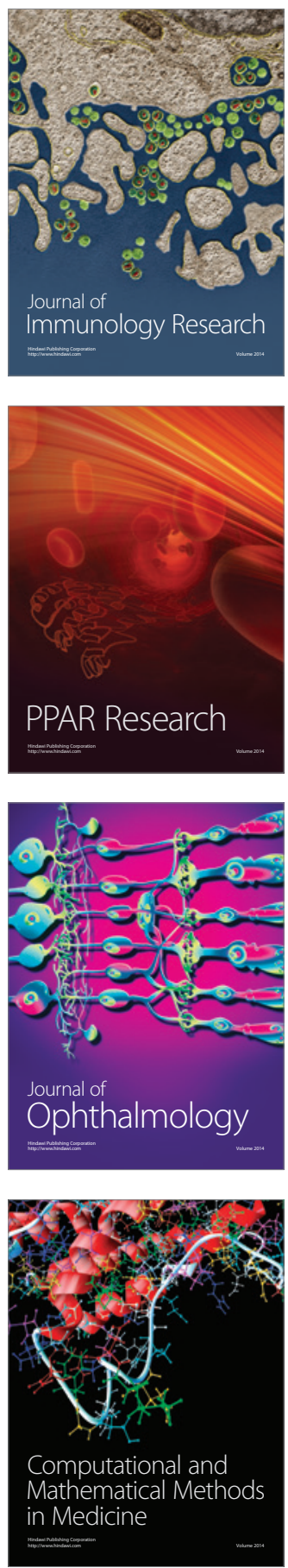

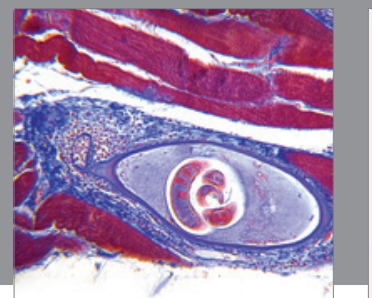

Gastroenterology

Research and Practice
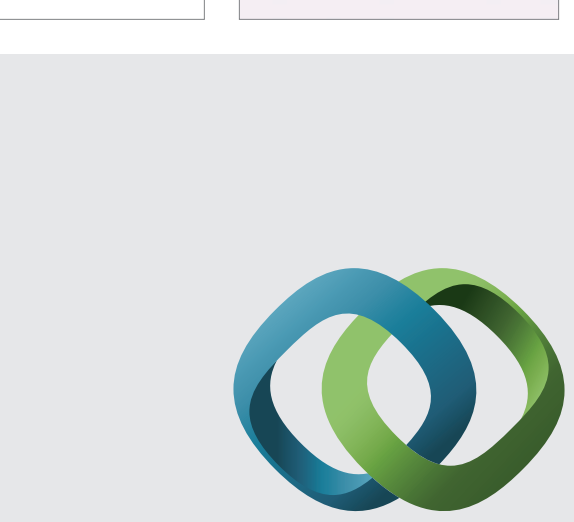

\section{Hindawi}

Submit your manuscripts at

http://www.hindawi.com
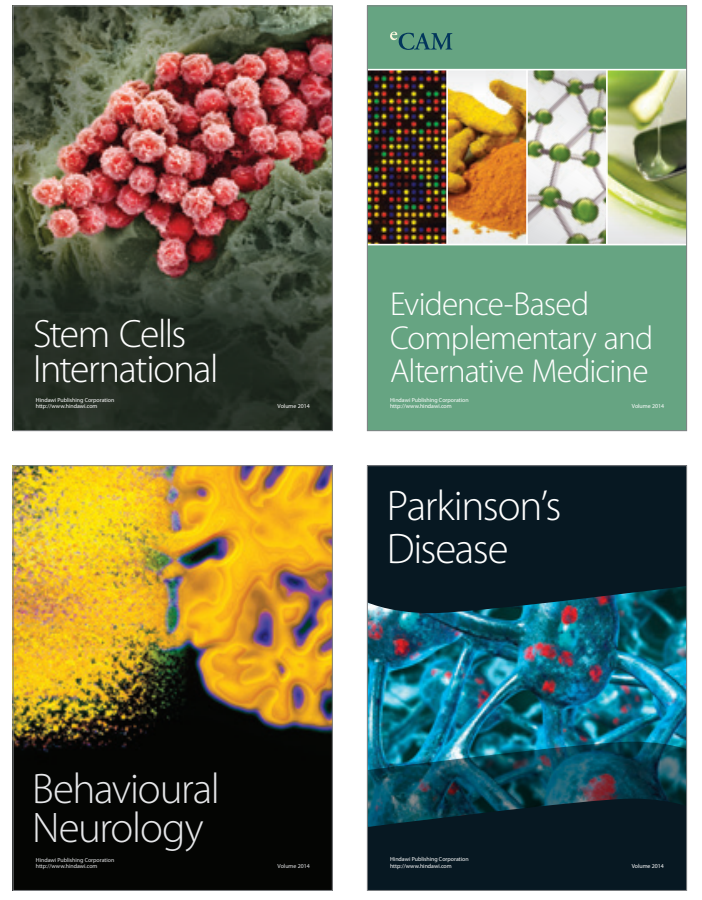
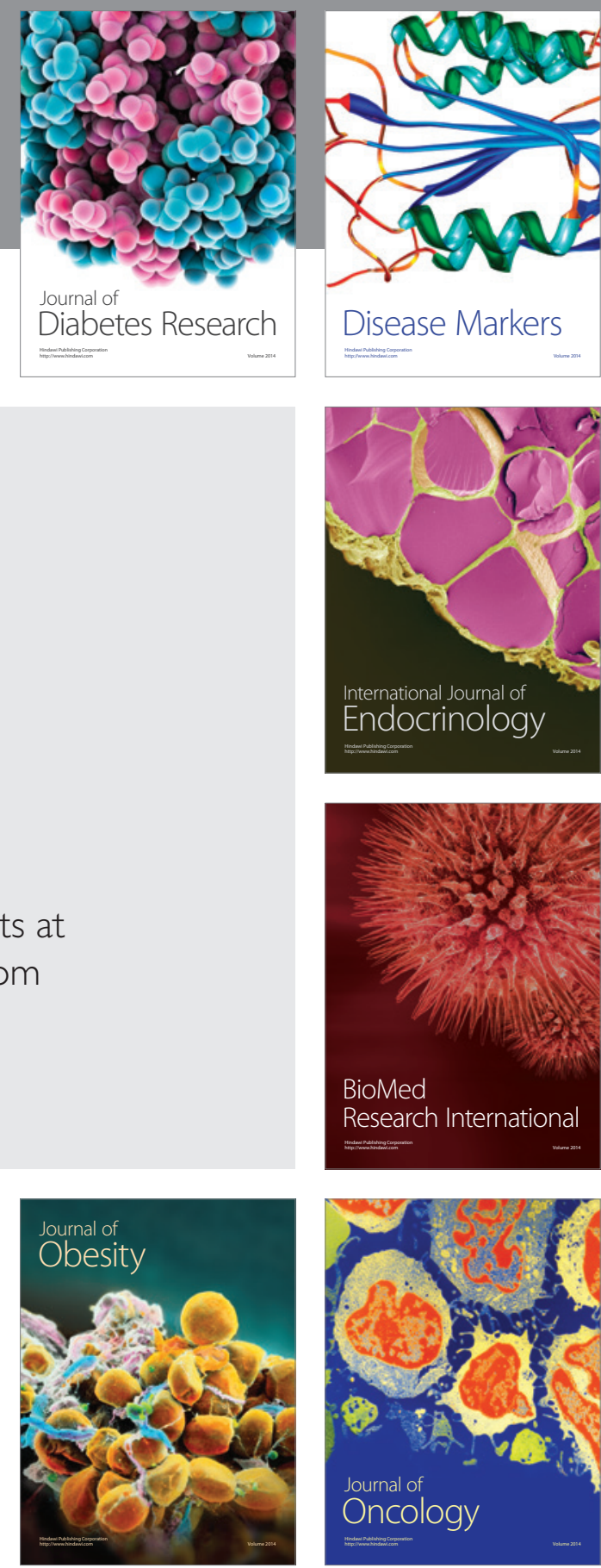

Disease Markers
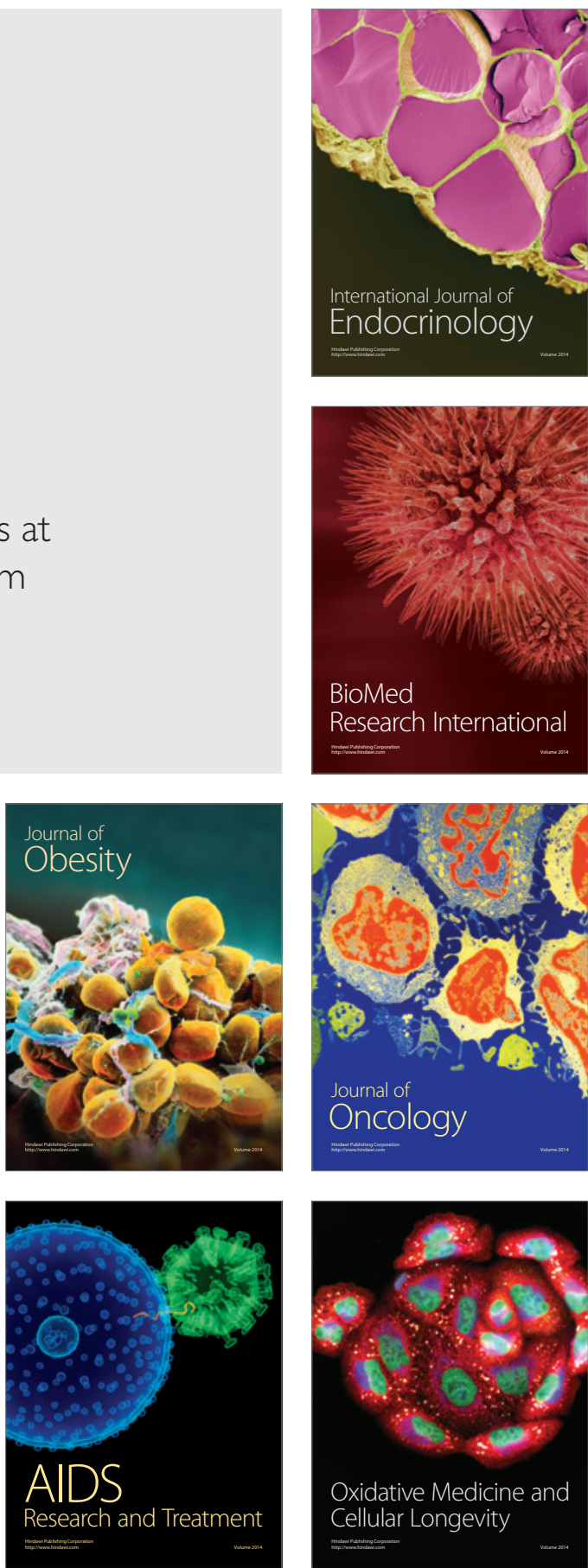